\title{
Full-Dimensional Ab Initio Potential Energy Surface and Vibrational Energy Levels of $\mathrm{Li}_{2} \mathrm{H}$
}

\author{
Michiko Ahn Furudate ${ }^{1}\left[\right.$, Denis Hagebaum-Reignier ${ }^{2, *} \mathbb{C}$ and Gwang-Hi Jeung ${ }^{2}$ \\ 1 Department of Mechatronics Engineering, Chungnam National University, Daejeon 34134, Korea; \\ furu@cnu.ac.kr \\ 2 Aix Marseille Univ, CNRS, Centrale Marseille, iSm2, F-13397 Marseille, France; gwang-hi.jeung@univ-amu.fr \\ * Correspondence: denis.hagebaum-reignier@univ-amu.fr; Tel.: +33-491-288-918
}

Received: 21 November 2018; Accepted: 18 December 2018; Published: 21 December 2018

\begin{abstract}
We built a full-dimensional analytical potential energy surface of the ground electronic state of $\mathrm{Li}_{2} \mathrm{H}$ from ca. 20,000 ab initio multi-reference configuration interaction calculations, including core-valence correlation effects. The surface is flexible enough to accurately describe the three dissociation channels: $\mathrm{Li}\left(2 \mathrm{~s}^{2} \mathrm{~S}\right)+\mathrm{LiH}\left({ }^{1} \Sigma^{+}\right), \mathrm{Li}_{2}\left({ }^{1} \Sigma_{\mathrm{g}}{ }^{+}\right)+\mathrm{H}\left(1 \mathrm{~s}^{2} \mathrm{~S}\right)$ and $2 \mathrm{Li}\left(2 \mathrm{~s}^{2} \mathrm{~S}\right)+\mathrm{H}\left(1 \mathrm{~s}^{2} \mathrm{~S}\right)$. Using a local fit of this surface, we calculated pure $(J=0)$ vibrational states of $\mathrm{Li}_{2} \mathrm{H}$ up to the barrier to linearity (ca. $3400 \mathrm{~cm}^{-1}$ above the global minimum) using a vibrational self-consistent field/virtual state configuration interaction method. We found 18 vibrational states below this barrier, with a maximum of 6 quanta in the bending mode, which indicates that $\mathrm{Li}_{2} \mathrm{H}$ could be spectroscopically observable. Moreover, we show that some of these vibrational states are highly correlated already ca. $1000 \mathrm{~cm}^{-1}$ below the height of the barrier. We hope these calculations can help the assignment of experimental spectra. In addition, the first low-lying excited states of each $B_{1}, B_{2}$ and $A_{2}$ symmetry of $\mathrm{Li}_{2} \mathrm{H}$ were characterized.
\end{abstract}

Keywords: potential energy surface; multi-reference configuration interaction; vibrational configuration interaction; $\mathrm{Li}_{2} \mathrm{H}$; dilithium hydride; excited states

\section{Introduction}

It is well known that the most characteristic property of the metal atom in a molecular complex is its facility of spontaneously yielding electrons to the surrounding ligands or the surrounding solvent molecules. Among metal atoms, alkali atoms are the most easily electron yielding, as their first ionization potentials are the lowest due to their single-valence electron structure. The electron transfer from the metal atom to the ligand also depends on the ligand's electron affinity, which in turn depends on the electronic structure of the ligand. The degree of ionicity of a given chemical bonding, as measured by the electron distribution, also depends on the atomic spectra of the metal atom (i.e., its ground and excited states), the electron affinity of the ligand, and the strong perturbation caused by putting the metal atom and the ligand together [1]. The hydrogen atom as ligand makes a moderate ionic bond with metal atoms due to its relatively low electron affinity of about $0.756 \mathrm{eV}$ [2]. Low electron affinity, on the other hand, causes a strong perturbation to many of the excited electronic states in metal hydrides. As a result, the excited states of metal hydride molecules show many interesting properties.

When instead of one metal atom, two metal atoms are brought into the proximity of the ligand, not all valence electrons can participate in the chemical bonding to stabilize the complex. Those valence electrons that do not participate to the bonding constitute the so-called non-bonding electrons, and their role is rather secondary as far as bond energy is concerned. According to the states of the non-bonding electrons, i.e., according to the molecular orbital occupations and the spin states, 
several molecular states close to the ground state result. The existence of the two metal atoms also makes ionization easy, resulting in a corresponding cation complex. In this work, we studied a small system- $\mathrm{Li}_{2} \mathrm{H}$, consisting of two lithium atoms and one hydrogen atom-with the most advanced first-principle (ab initio) quantum chemical methods.

Apart from its interesting molecular properties, lithium hydride possesses very useful electrochemical properties, as it is expected to be used as the hydrogen storage material in fuel cells, because lithium is the lightest element that can form solid-state compounds with hydrogen [3].

There are numerous theoretical studies in the literature on the $\mathrm{Li}_{2} \mathrm{H}$ complex, which we briefly summarize here. The first electronic structure calculations for $\mathrm{Li}_{2} \mathrm{H}$ were carried out using the self-consistent field (SCF) and full configuration interaction (CI) techniques by Siegbahn et al. [4] and England et al. [5] in the 1970s. The latter work already contained correlated multi-configurational SCF/CI (MCSCF/CI) calculations on the lowest ${ }^{2} \mathrm{~A}_{1},{ }^{2} \mathrm{~B}_{2}$ and ${ }^{2} \Sigma$ states of $\mathrm{Li}_{2} \mathrm{H}$. Some of these were confirmed by Talbi et al. [6] in their study of the low-lying states of $\mathrm{Li}_{3} \mathrm{H}$. In the 1990s, unrestricted Møller-Plesset perturbation methods (UMP) were applied to study the energetics and structure of the electronic ground state of $\mathrm{Li}_{2} \mathrm{H}$ [7] and some low-lying states of $\mathrm{Li}_{2} \mathrm{H}$ [8]. Allouche et al. [9] provided a detailed analysis of the six low-lying states of $\mathrm{Li}_{2} \mathrm{H}$ (two of each $\mathrm{A}_{1}, \mathrm{~B}_{1}$ and $\mathrm{B}_{2}$ symmetry) using a complete active space self-consistent field approach (CASSCF) and tentatively assigned the origin of two observed bands in an optical absorption spectrum of $\mathrm{Li}_{2} \mathrm{H}$ [10,11]. These last two studies [8,9] and the early study of England et al. [5] are the only reports so far about the electronic states of $\mathrm{Li}_{2} \mathrm{H}$ other than the ground $\mathrm{X}^{2} \mathrm{~A}_{1}$ and the first excited states. The first global analytical PES using a bond-order polynomial expansion to best fit $394 \mathrm{ab}$ initio points of full-CI (FCI) quality was due to Maniero et al. in 2010 [12]. More recently, Song et al. [13] developed a potential energy surface (PES) for the electronic ground state of $\mathrm{Li}_{2} \mathrm{H}$ using double many-body expansion fitting based on $3726 \mathrm{ab}$ initio energies calculated at the multi-reference configuration interaction (MRCI) level. Yuan et al. [14] also developed a PES fitting in a many-body expansion manner from 30,000 ab initio energies calculated at the MRCI-F12 level. These PESs have been used in recent time-dependent quantum dynamical studies on the $\mathrm{H}+\mathrm{Li}_{2}\left(X^{1} \Sigma^{+} \mathrm{g}\right)$ reaction [14-18]. It was shown that the rovibrational excitation of $\mathrm{Li}_{2}$ inhibits the reaction, and that the Coriolis coupling is highly relevant in this complex-forming reaction via an insertion mechanism.

The experimental data on $\mathrm{Li}_{2} \mathrm{H}$ is scarce. Apart from the two-photon absorption spectrum of $\mathrm{Li}_{2} \mathrm{H}[10,11]$, the only study that has proved the existence of a stable $\mathrm{Li}_{2} \mathrm{H}$ molecule is that of $\mathrm{Wu}$ and Ihle [19], from mass spectrometric measurements performed at about $900 \mathrm{~K}$ of two gaseous reactions involving $\mathrm{Li}_{2} \mathrm{H}$. These authors estimated the ionization energy of $\mathrm{Li}_{2} \mathrm{H}$ to be $4.5 \pm 0.2 \mathrm{eV}$ and recommended an experimental atomization energy of $89.7 \pm 5 \mathrm{kcal} \cdot \mathrm{mol}^{-1}$. However, the latter value was obtained from indirect measurements of equilibrium enthalpies and has to be taken with caution, as we will discuss in the results section. Crooks et al. [20] recorded the photoionization spectrum, showing many vibrational structures, but they could not well resolve them.

Our first aim in this work is to calculate the vibrational energy levels of $\mathrm{Li}_{2} \mathrm{H}$ from a new global analytical PES of the ground electronic state. To achieve this, a grid of high-level ab initio points was fitted using the efficient monomial symmetrization approach (MSA) [21], and the vibrational energies and wave functions were calculated using the MULTIMODE program (version v.3.9, Emory University, Atlanta, GA, USA) [22]. Although the available global analytical PESs are of high quality, none of them includes the core-valence correlation effect. It is, however, expected to be important for alkali species, and is thus desirable in order to approach quantitative accuracy. Indeed, Rosmus and Meyer [23] and Jeung et al. [24] have shown that the inclusion of this effect increases the ionization energy in better agreement with the experimental data, and Jeung et al. [25] have shown that the inclusion of this effect gives better atomic excitation energies too. Therefore, our motivation to build a new global PES was to also include this effect. Last, we also wanted to characterize the first low-lying excited electronic states of $\mathrm{Li}_{2} \mathrm{H}$ and the ground state of $\mathrm{Li}_{2} \mathrm{H}^{+}$. 


\section{Calculation Details}

\subsection{Ab Initio Calculations}

We performed ab initio calculations at the Multi-Reference Configuration Interaction Single Double (MRCISD) level using large basis sets for $\mathrm{Li}$ and $\mathrm{H}$. These basis sets consist of uncontracted 6s4p2d Gaussian functions for $\mathrm{H}$ and 11s6p3d1f (7s6p3d1f) functions for $\mathrm{Li}$. The Li basis set is slightly reduced from that found in [26], where four s-type and four p-type diffuse functions were removed, as this basis set was originally designed to calculate high-lying Rydberg atomic and molecular electronic states. This basis set was optimized (by minimizing the energies) in the atomic CI calculation, including the core-valence and core-core effects, in particular for the Rydberg states. The primitive functions of the $\mathrm{H}$ basis set remain unchanged. Unless otherwise mentioned, the present basis set will be referred to in the following as the J99 basis (see Supplementary Materials). The aug-cc-pCVTZ, cc-pCVQZ and cc-pCV5Z basis sets of Dunning [27] (hereafter denoted as ACVTZ, CVQZ and CV5Z, respectively) were also used for comparison with other calculations from the literature. Please note that the (A)CVXZ basis sets are the same as the (A)VXZ basis sets, but augmented with some extra functions to account for core-valence effects. When these effects are neglected in the calculation, the (A)CVXZ basis sets lead to almost identical results as those of the (A)VXZ basis. The Dunning's basis sets have a larger number of atomic basis functions compared to J99; thus, the former require a lot more computational resources. We compared the computational resources required for different basis sets. Around the equilibrium geometry of $\mathrm{Li}_{2} \mathrm{H}$, $\mathrm{J99}$ uses about $1 / 6$ as much storage space as CVQZ and 1/50 as much as CV5Z. J99 also uses $1 / 5$ as much total CPU time as CVQZ and $1 / 26$ of the CPU time required by CV5Z. Considering its accuracy (as will be discussed in Section 3.1 and in the Supplementary Materials, Table S2), we adopted J99 to explore the potential energy surfaces in this work.

The reference molecular orbitals (MOs) for the MRCI calculations were obtained by the complete active space (CAS) self-consistent field (SCF) method, with the active space determined by all valence atomic orbitals (FVCAS). The core orbitals of the two lithium atoms were kept inactive in the CASSCF calculations, i.e., they were doubly occupied in all reference configuration state functions (CSFs), but were correlated at the $\mathrm{CI}$ level. The core-core and core-valence correlation effects were included by allowing all single and double excitations from all the reference CSFs, leading to about $6 \times 10^{5} \mathrm{CSFs}$. Please note that the Davidson correction was not taken into account in the present study. It usually corrects size-extensivity and size-consistency problems of truncated CI methods (like MRCISD). For the $\mathrm{Li}_{2} \mathrm{H}$ system, we found that this correction was less than $0.2 \mathrm{kcal} \cdot \mathrm{mol}^{-1}$ on the values of the dissociation energies. Davidson correction and other variant types are useful only for cases where the $\mathrm{CI}$ is quite truncated, so its use with large-scale CI should be avoided. In addition, Born-Oppenheimer and relativistic corrections, as well as higher-order correlation effects, were neglected. These corrections are expected to be smaller in magnitude compared to the core-core and core-valence correlation effects, and taking these corrections into account is beyond the scope of our study. Since we study the whole surface of the ground state from the global minimum to dissociation channels, as well as some excited states, the choice of multireference methods ensures a proper description of the static correlation.

The valence coordinates $r_{H L i}$ and $\theta_{L i H L i}$ were used to generate a grid of $\approx 2 \times 10^{4} \mathrm{MRCI}$ points, which were randomly chosen within the following ranges: $1.5 \leq r_{H L i} \leq 12$ [a.u.] and $0<\theta_{L i H L i}<180$ [deg]. All ab initio calculations, as well as Vibrational Configuration Interaction (VCI) calculations (see Section 3.4), were performed using the MOLPRO 2012.1 software (version 2012.1, Stuttgart University, Stuttgart, Germany) [28]. The distribution of points is analyzed and discussed in Section 3.2.

\subsection{Potential Energy Surface Fitting}

We built a global analytical representation of the ab initio PES, based on the monomial symmetrization approach developed by Bowman's group [21]. This method relies on the use of fitting basis functions that are invariant by permutation of like atoms. It makes it possible to efficiently 
fit several thousand ab initio energies. The potential is expressed as a sum of symmetrized monomials that are functions of the Morse variables $x_{i}$, which in turn depend on the internuclear distances $r_{i j}$ :

$$
\left(x_{1}, x_{2}, x_{3}\right)=\left(e^{-r_{12} / \lambda}, e^{-r_{13} / \lambda}, e^{-r_{23} / \lambda}\right)
$$

where $\lambda$ is a constant parameter $\left(\lambda=3 \mathrm{a}_{0}\right)$, and $\left(r_{12}, r_{13}, r_{23}\right)=\left(r_{L i_{1} L i_{2}}, r_{L i_{1} H}, r_{L i_{2} H}\right)$. The expression for $V$ is:

$$
V\left(x_{1}, x_{2}, x_{3}\right)=\sum_{a+b+c=0}^{k} C_{a, b, c} x_{1}^{a}\left(x_{2}^{b} x_{3}^{c}+x_{3}^{b} x_{2}^{c}\right)
$$

where $a, b$ and $c$ are non-negative integers, and $k$ is a positive integer that sets the total order of the polynomial. The fitting procedure relies on a standard linear least-squares algorithm.

\subsection{Vibrational Energy Calculation}

Using the analytical representation of the potential, we computed accurate pure vibrational energy levels $(J=0)$ using the MULTIMODE program [22]. This is based on the following Watson Hamiltonian $\hat{H}_{W}$ (in atomic units), which is only valid for non-linear molecules:

$$
\hat{H}_{W}=\frac{1}{2} \sum_{\alpha \beta} \hat{\pi}_{\alpha} \mu_{\alpha \beta} \hat{\pi}_{\beta}-\frac{1}{8} \sum_{\alpha} \hat{\mu}_{\alpha \alpha}-\frac{1}{2} \sum_{i} \frac{\partial^{2}}{\partial Q_{i}^{2}}+V\left(Q_{1}, \ldots, Q_{N}\right)
$$

The first term is the Coriolis coupling term and involves the inverse of the moment of inertia tensor $\mu$, as well as the vibrational angular momentum $\hat{\pi}_{\alpha}$, as defined in [29]. The second term is the so-called Watson correction term. The full potential $V\left(Q_{1}, \ldots, Q_{N}\right)$ depends on the mass-scaled normal coordinates $Q_{i}$ and is expanded as a hierarchical sum of $n$-mode contributions. For a triatomic molecule $(N=3)$, the potential reads:

$$
V\left(Q_{1}, Q_{2}, Q_{3}\right)=\sum_{i=1}^{3} V_{i}^{(1)}\left(Q_{i}\right)+\sum_{i<j}^{3} V_{i j}{ }^{(2)}\left(Q_{i}, Q_{j}\right)+V_{123}{ }^{(3)}\left(Q_{1}, Q_{2}, Q_{3}\right)
$$

where the $n$-mode contributions, $V^{(n)}$, are given by the full potential with all $Q_{k}$ except $Q_{i}$ equal to zero for $n=1$, and all $Q_{k}$ except $Q_{i}$ and $Q_{j}$ equal to zero for $n=2$. The eigenvalues of the Watson Hamiltonian are obtained by a vibrational self-consistent field/virtual state configuration interaction (hereafter named V-CI) approach. For a triatomic molecule, $\mathrm{V}-\mathrm{CI}$ calculations $(J=0)$ give variational and "exact" vibrational energy levels. As mentioned above, this approach will fail for ground state linear molecules since the Coriolis and Watson terms will diverge, as it may also fail for states lying above the barrier to linearity. However, as long as there are not too many quanta in the bending mode, those high-lying vibrational energy levels should remain accurate.

\section{Results and Discussion}

\subsection{Ab Initio Calculations for Atomic and Diatomic Species}

The electronic energies of atomic species $\mathrm{H}, \mathrm{Li}$, and $\mathrm{Li}^{+}$calculated with four different basis sets (see Section 2.1) are reported in the Supplementary Materials (Table S1). The J99 is in excellent agreement with experimental atomic excitation or ionization energies (within less than $0.3 \%$ error) when core-valence correlation effects are included. It is shown that the J99 basis is a reasonable basis that requires low computational cost, as mentioned earlier, and has comparable quality to Dunning's basis (ACVTZ, CVQZ and CV5Z, with or without core-valence effects). The same trend is observed for the diatomic species $\mathrm{LiH}$ and $\mathrm{Li}_{2}$ (see Table S2): the equilibrium distances, dissociation energies and vertical ionization energies of both diatomics are in reasonably good agreement with experimental values and the recent aug-cc-pVTZ/MRCI-F12 calculations of Yuan et al. [14]. The agreement is better 
when the core-valence correlation is taken into account, except for the diatomic dissociation energies, for which the differences are less than $1 \mathrm{kcal} \cdot \mathrm{mol}^{-1}\left(=350 \mathrm{~cm}^{-1}\right)$. In the light of these results, one can be confident on the quality of the chosen basis set and method for the calculation on $\mathrm{Li}_{2} \mathrm{H}$ triatomic complex. Although spectroscopic accuracy is not reached for diatomic dissociation energies, one may expect cancellation of errors for the estimation of reaction enthalpies.

\subsection{Ab Initio Calculations for the $\mathrm{Li}_{2} \mathrm{H}$ Triatomic Complex}

In Table 1, we report our calculated values of equilibrium geometries, atomization, dissociation and ionization energies of the dilithium hydride complex, as well as those from the literature for comparison. As for the atomic and diatomic species, we examine here the effects of the basis sets and core-valence correlation on these properties. Regarding the equilibrium geometries, core-valence correlation effects tend to shorten the equilibrium H-Li bond lengths by ca. 0.02 a.u., and decrease the equilibrium $\angle(\mathrm{Li}-\mathrm{H}-\mathrm{Li})$ angle by less than 1 degree, regardless of the basis set. The atomization energy, the dissociation energies in both the $\mathrm{Li}_{2}\left({ }^{1} \Sigma_{\mathrm{g}}{ }^{+}\right)+\mathrm{H}\left(1 \mathrm{~s}{ }^{2} \mathrm{~S}\right)$ and $\mathrm{Li}\left(2 \mathrm{~s}{ }^{2} \mathrm{~S}\right)+$ $\mathrm{LiH}\left({ }^{1} \Sigma^{+}\right)$channels $\left(\mathrm{E}_{\text {diss1 }}\right.$ and $\mathrm{E}_{\text {diss2 }}$ respectively) as well as the ionization energy are larger when the core-valence correlation is taken into account. The largest deviations appear on the ionization energies (ca. $0.03 \mathrm{eV}=0.7 \mathrm{kcal} \cdot \mathrm{mol}^{-1}$ ) and on the atomization energies (ca. $0.3 \mathrm{kcal} \cdot \mathrm{mol}^{-1}$ ). In the Dunning basis set series $\mathrm{ACVTZ}<\mathrm{CVQZ}<\mathrm{CV} 5 \mathrm{Z}$, the atomization energies continuously increases, with a difference between ACVTZ and CV5Z of $0.9 \mathrm{kcal} \cdot \mathrm{mol}^{-1}$, regardless of core-valence correlation effects.

Table 1. Comparison of equilibrium geometries and energies of the ground electronic state $\mathrm{X}^{2} \mathrm{~A}_{1}$ of $\mathrm{Li}_{2} \mathrm{H}$.

\begin{tabular}{|c|c|c|c|c|c|c|c|c|c|}
\hline $\begin{array}{c}\mathrm{Li}_{2} \mathrm{H} \\
\left(\mathrm{X}^{2} \mathrm{~A}_{1}\right)\end{array}$ & Method & Basis & c.v. ${ }^{a}$ & $\begin{array}{c}R_{e \text { Li-H }} \\
\text { [a.u.] }\end{array}$ & $\begin{array}{l}\angle \text { LiHLi } \\
\text { [degrees] }\end{array}$ & 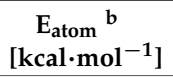 & $\begin{array}{c}\mathrm{E}_{\text {diss } 1}{ }^{\mathrm{c}} \\
{\left[\mathrm{kcal} \cdot \mathrm{mol}^{-1}\right]}\end{array}$ & 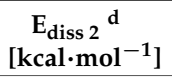 & $\begin{array}{c}E_{\text {ion }} \mathrm{e} \\
{[\mathrm{eV}]}\end{array}$ \\
\hline \multirow[t]{9}{*}{ Present } & MRCI & J99 & $\mathrm{Y}$ & 3.233 & 93.70 & 82.05 & 58.39 & 25.25 & 4.671 \\
\hline & MSA fitting & J99 & $\mathrm{Y}$ & 3.234 & 92.93 & 82.11 & 56.44 & 26.71 & - \\
\hline & MRCI & CV5Z & $\mathrm{Y}$ & 3.227 & 93.60 & 83.04 & 58.98 & 25.34 & 4.683 \\
\hline & MRCI & CVQZ & $\mathrm{Y}$ & 3.231 & 93.66 & 82.79 & 58.78 & 25.26 & 4.678 \\
\hline & MRCI & ACVTZ & $\mathrm{Y}$ & 3.240 & 93.59 & 82.11 & 58.24 & 25.12 & 4.672 \\
\hline & MRCI & J99 & $\mathrm{N}$ & 3.253 & 94.04 & 82.00 & 58.26 & 24.94 & 4.642 \\
\hline & MRCI & CV5Z & $\mathrm{N}$ & 3.254 & 93.95 & 82.70 & 58.62 & 25.15 & 4.646 \\
\hline & MRCI & CVQZ & $\mathrm{N}$ & 3.256 & 93.88 & 82.52 & 58.48 & 25.10 & 4.647 \\
\hline & MRCI & ACVTZ & $\mathrm{N}$ & 3.262 & 93.76 & 81.80 & 57.99 & 24.93 & 4.647 \\
\hline Yuan $\mathrm{g}$ & MRCI-F12 & AVTZ & $\mathrm{N}$ & 3.220 & 94.37 & 86.64 & 61.4 & 27.4 & \\
\hline \multirow[t]{3}{*}{ Song ${ }^{\mathrm{h}}$} & Fitting & $\begin{array}{c}\text { DMBE/SEC } \\
\text { PES }\end{array}$ & $\mathrm{N}$ & 3.247 & 94.31 & 87.91 & 65.0 & 31.3 & \\
\hline & MRCI & V5Z & $\mathrm{N}$ & 3.252 & 94.14 & 84.39 & & & \\
\hline & MRCI & VQZ & $\mathrm{N}$ & 3.256 & 93.95 & 82.56 & & & \\
\hline Maniero $^{i}$ & $\begin{array}{l}\text { Fitting (Full } \\
\text { CI) }\end{array}$ & $\begin{array}{l}\text { pseudo-poten } \\
\text { 6-311G (2df, } \\
\text { 2pd) }\end{array}$ & $\mathrm{N}$ & 3.221 & 94.65 & 86.9 & & & \\
\hline Vezin ${ }^{j}$ & Exp. & & & 3.241 & 94.70 & & & & \\
\hline \multirow[t]{2}{*}{$\mathrm{Wu}^{\mathrm{k}}$} & $\begin{array}{l}\text { Exp. } \\
\text { (linear) }\end{array}$ & & & & & $87.9 \pm 3^{f}$ & & & $4.5 \pm 0.3$ \\
\hline & Exp. (bent) & & & & & $82.1 \pm 3$ & & & \\
\hline $\begin{array}{l}\text { From } W_{u}{ }^{\mathrm{f}} \text {, } \\
\text { Verma }^{1} \text { and } \\
\text { Stwalley }\end{array}$ & Exp. & & & & & & $63.4 \pm 3$ & $29.8 \pm 3$ & \\
\hline $\begin{array}{l}{ }^{\mathrm{a}} \mathrm{c} . \mathrm{V} .: \mathrm{cc} \\
\mathrm{E}\left(\mathrm{Li}_{2} \mathrm{H}\right) \\
\mathrm{Li}_{2} \mathrm{H} \rightarrow \\
\text { value in }\end{array}$ & $\begin{array}{l}\text {-core and c } \\
\mathrm{Li}_{2} \mathrm{H} \rightarrow \mathrm{Li}_{2} \\
\mathrm{i}_{2} \mathrm{H}^{+}, \mathrm{E}_{\mathrm{ion}}= \\
\text { Ref. [30]; } \mathrm{g} \mathrm{R}\end{array}$ & $\begin{array}{l}\text { e-valence cor } \\
\mathrm{H}, \mathrm{E}_{\text {diss } 1}=\mathrm{E}( \\
\left.\mathrm{Li}_{2} \mathrm{H}^{+}\right)-\mathrm{E}(\mathrm{L} \\
{[14] ;{ }^{\mathrm{h}} \text { Ref. [ }}\end{array}$ & $\begin{array}{l}\text { lati } \\
\text { 2) }+ \\
\text { H); } \\
\text { ]; }{ }^{\text {i }} \mathrm{I}\end{array}$ & $\begin{array}{l}\text { includ } \\
-\mathrm{E}( \\
\text { rersion } \\
12] ;{ }^{\mathrm{j}} \mathrm{F}\end{array}$ & $\begin{array}{l}\text { Y) or not } \\
\text { I); }{ }^{d} \mathrm{Li}_{2} \mathrm{H} \\
\text { tors: } 1 \mathrm{eV} \\
{[11] ; \mathrm{k} \mathrm{Re}}\end{array}$ & $\begin{array}{l}(\mathrm{N}) ;^{\mathrm{b}} \mathrm{Li}_{2} \mathrm{H} \rightarrow \\
\rightarrow \mathrm{Li}+\mathrm{LiH}, \mathrm{E} \\
=23.061 \mathrm{kcal} \cdot \mathrm{n} \\
\text { f. [19]; }{ }^{1} \text { Ref. [3 }\end{array}$ & $\begin{array}{l}2 \mathrm{Li}+\mathrm{H}, \mathrm{E}_{\text {atom }} \\
\text { diss } 2=\mathrm{E}(\mathrm{Li})+\mathrm{H} \\
\mathrm{mol}^{-1}=8065.5 \\
1] \text {; }^{\mathrm{m}} \text { Ref. [32] }\end{array}$ & $\begin{array}{l}=2 \mathrm{E}(\mathrm{Li})+\mathrm{E} \\
\mathrm{E}(\mathrm{LiH})-\mathrm{E}(\mathrm{Li} \\
4 \mathrm{~cm}^{-1} ;{ }^{\mathrm{f}} \mathrm{Cor}\end{array}$ & $\begin{array}{l}\text { H) - } \\
\text { H); } \\
\text { ected }\end{array}$ \\
\hline
\end{tabular}

In what follows, we compare the present results with calculations from the literature and with the scarce experimental data. Our best calculated equilibrium $\mathrm{H}-\mathrm{Li}$ bond lengths (3.233 a.u.) and $\angle(\mathrm{Li}-\mathrm{H}-\mathrm{Li}$ ) (93.7 degree) differ from less than 0.02 a.u. and 0.9 degree from the most recent calculations [12-14]. The comparison of our MRCI/ACVTZ values with the explicitly correlated values of Yuan et al. shows the important influence of the explicit-correlation: distances are shorter by ca. 0.04 a.u. and atomization (resp. $\mathrm{E}_{\text {diss 1 }}$ ) values are greater by ca. 5 (resp. 3) $\mathrm{kcal} \cdot \mathrm{mol}^{-1}$, when explicit-correlation is taken into account. Our values reproduce the experimental data with a $2 \%$ error on the equilibrium $\mathrm{H}-\mathrm{Li}$ bond length, and less 
than $1 \%$ error for the equilibrium $\angle(\mathrm{Li}-\mathrm{H}-\mathrm{Li})$. Our calculated value of the adiabatic ionization potential $(4.671 \mathrm{eV})$ is in excellent agreement with the experimental value $(4.5 \mathrm{eV})$ and within the experimental error range of $\pm 0.3 \mathrm{eV}$. Our best estimation of the atomization energy and dissociation energies in the $\mathrm{Li}_{2}+\mathrm{H}$ and $\mathrm{LiH}+\mathrm{Li}$ channels (MRCI level considering core-valence correlation with the J99 basis) are 82.05, 58.39 and $25.25 \mathrm{kcal} \cdot \mathrm{mol}^{-1}$, respectively. These are all smaller by $4.6,3.0$ and $2.2 \mathrm{kcal} \cdot \mathrm{mol}^{-1}$, respectively, than the MRCI-F12 values of Yuan et al. [14], and up to $5.85 \mathrm{kcal} \cdot \mathrm{mol}^{-1}$ for the atomization energy compared with the experimental value and Song's values [13]. We want to critically comment on these values here. First, the apparent excellent agreement between Song's atomization energy value and the experimental one seems rather artificial, since their PES was scaled to the experimental value. Second, regarding this particular experimental value, it has to be taken with caution, as it was indirectly derived from reaction enthalpies, whereby two different assumptions for the structure of $\mathrm{Li}_{2} \mathrm{H}$ were considered. The originally suggested value of $89.7 \pm 5 \mathrm{kcal} \cdot \mathrm{mol}^{-1}$, later corrected by Kim and Herschbach [30] to $87.9 \pm 3 \mathrm{kcal} \cdot \mathrm{mol}^{-1}$, was estimated from an average value of two atomization energies assuming a linear $\mathrm{Li}_{2} \mathrm{H}$ geometry, which is obviously not consistent with all calculations from the literature. Furthermore, these two atomization energies were obtained from linear regression of equilibrium constants of two different reactions and from the knowledge of experimental dissociation energies of $\mathrm{Li}_{2}, \mathrm{LiH}$ and $\mathrm{Li}_{3}$ molecules. Another estimate from the same authors using a triangular geometry was $82.1 \pm 3 \mathrm{kcal} \cdot \mathrm{mol}^{-1}$ (see Table 1 ), which appears more consistent with our best calculated value.

We also calculated the equilibrium geometries and energies of the excited $B_{2}, B_{1}$, and $A_{2}$ states of $\mathrm{Li}_{2} \mathrm{H}$. We compare our results with calculations from the literature in Table 2. The present calculations were carried out assuming $\mathrm{C}_{2 \mathrm{v}}$ symmetry, as in past studies. The obtained geometries and energies agree well with the past calculations. Among the states we calculated, we found that the lowest $1^{2} \mathrm{~B}_{2}$ and the highest $1^{2} \mathrm{~A}_{2}$ excited states are both linear, and the intermediate $1^{2} \mathrm{~B}_{1}$ has a bent geometry, with a wider $\mathrm{Li}-\mathrm{H}-\mathrm{Li}$ angle than in the ground state geometry. Our excitation energies are in best agreement with the values of Allouche et al. [9] for the $1^{2} \mathrm{~B}_{2}$ and $1^{2} \mathrm{~B}_{1}$, and differ by only $630 \mathrm{~cm}^{-1}$ from the UMP2 values of Fang et al. [8] over a $17,428 \mathrm{~cm}^{-1}$ transition. The present equilibrium $\mathrm{Li}-\mathrm{H}$ bond length is longer in these states than those in the past studies, except the value of Talbi et al. [6]. The $\mathrm{Li}_{2} \mathrm{H}^{+}$cation is found to be linear, and our adiabatic and vertical ionization energies are less than $1000 \mathrm{~cm}^{-1}$ smaller than those of Allouche et al. [9].

Table 2. Equilibrium geometries and excitation energies of the low-lying excited states of $\mathrm{Li}_{2} \mathrm{H}$ and of $\mathrm{Li}_{2} \mathrm{H}^{+}$with respect to the $\mathrm{X}^{2} \mathrm{~A}_{1}$ ground state.

\begin{tabular}{|c|c|c|c|c|c|}
\hline $\mathrm{Li}_{2} \mathrm{H}\left(\mathbf{1}^{2} \mathrm{~B}_{2}\right)$ & Method & $R_{e \text { Li-H }}$ [a.u.] & $\angle$ LiHLi [degrees] & \multicolumn{2}{|c|}{$\mathrm{E}-\mathrm{E}\left(\mathrm{X}^{2} \mathrm{~A}_{1}\right)\left[\mathrm{cm}^{-1}\right]$} \\
\hline Present & MRCI & 3.174 & 180.0 & \multicolumn{2}{|c|}{3581.7} \\
\hline Talbi ${ }^{\text {a }}$ & $\mathrm{MCSCF} / \mathrm{SOCI}$ & 3.222 & 180 & \multicolumn{2}{|c|}{3382} \\
\hline Allouche ${ }^{b}$ & CASSCF & 3.137 & 180 & \multicolumn{2}{|c|}{3597} \\
\hline Fang ${ }^{c}$ & UMP2 & 3.162 & 179.90 & \multicolumn{2}{|c|}{3458.9} \\
\hline $\mathrm{Li}_{2} \mathrm{H}\left(\mathbf{1}^{2} \mathrm{~B}_{1}\right)$ & Method & $R_{e \text { Li-H }}$ [a.u.] & $\angle$ LiHLi [degrees] & \multicolumn{2}{|c|}{$\mathrm{E}-\mathrm{E}\left(\mathrm{X}^{2} \mathrm{~A}_{1}\right)\left[\mathrm{cm}^{-1}\right]$} \\
\hline Present & MRCI & 3.035 & 131.6 & \multicolumn{2}{|c|}{8526.6} \\
\hline Allouche ${ }^{b}$ & CASSCF & 2.986 & 133 & \multicolumn{2}{|c|}{8554} \\
\hline Fang ${ }^{c}$ & UMP2 & 3.012 & 145.0 & \multicolumn{2}{|c|}{8719.7} \\
\hline $\mathrm{Li}_{2} \mathrm{H}\left(\mathbf{1}^{2} \mathrm{~A}_{2}\right)$ & Method & $R_{e \text { Li-H }}$ [a.u.] & $\angle$ LiHLi [degrees] & \multicolumn{2}{|c|}{$E-E\left(X^{2} A_{1}\right)\left[\mathrm{cm}^{-1}\right]$} \\
\hline Present & MRCI & 3.167 & 180.0 & \multicolumn{2}{|c|}{17428.3} \\
\hline Fang $^{c}$ & UMP2 & 3.140 & 179.89 & \multicolumn{2}{|c|}{16798.6} \\
\hline $\mathrm{Li}_{2} \mathrm{H}^{+}\left(\mathbf{1}^{1} \mathrm{~A}_{1}\right)$ & Method & $R_{e \text { Li-H }}$ [a.u.] & $\angle$ LiHLi [degrees] & \multicolumn{2}{|c|}{$\mathrm{E}-\mathrm{E}\left(\mathrm{X}^{2} \mathrm{~A}_{1}\right)\left[\mathrm{cm}^{-1}\right]$} \\
\hline Present & $\begin{array}{c}\text { MRCI } \\
\text { CASSCF }\end{array}$ & 3.104 & 180.0 & $\begin{array}{c}\text { adiabatic } \\
31654.3 \\
32584.8\end{array}$ & $\begin{array}{l}\text { vertical } \\
37673.4 \\
38392.0\end{array}$ \\
\hline$W u^{d}$ & Experiment & & & & 36295.0 \\
\hline
\end{tabular}




\subsection{Global Analytical PES of the Ground ${ }^{2} A_{1}$ State of $L i_{2} H$}

\subsubsection{MSA Fitting of PES}

The MRCI calculations are carried out for about 20,000 points in the range of $1.5<R_{\mathrm{LiH}}<12$ a.u. and $0<\theta_{\mathrm{LiHLi}}<180$ degrees. The distribution of the calculation points in the parameter space is shown in Figure 1, with the points colored according to the absolute energy value. About half of the points are chosen according to uniform random number generator in the range, and the others are concentrated near the global minimum energy point according to Gaussian distribution. Additionally, several hundred calculation points are added near the minimum energy path (MEP) from the global minimum energy point to the barrier to the linear conformation. Figure 2 shows the statistics on the number of calculation points against the energy measured from the global minimum energy at intervals of $100 \mathrm{~cm}^{-1}$. One can see three high peaks in the histogram at the energy intervals of $0 \sim 1000$, $8500 \sim 8600$, and $28,400 \sim 28,700 \mathrm{~cm}^{-1}$. The peak at $0 \sim 1000 \mathrm{~cm}^{-1}$ indicates that the calculation points are sufficiently concentrated near the global minimum energy value. The energy values of $8600 \mathrm{~cm}^{-1}$ $(25 \mathrm{kcal} / \mathrm{mol})$ and $28700 \mathrm{~cm}^{-1}(82 \mathrm{kcal} / \mathrm{mol})$ at the other two peaks correspond to the energies of the $\mathrm{LiH}+\mathrm{Li}$ asymptote, and the energy of the $2 \mathrm{Li}+\mathrm{H}$ atomic asymptote, respectively. This implies that these asymptotes are adequately captured in the present $\mathrm{ab}$ initio calculations. $\mathrm{The} \mathrm{H}+\mathrm{Li}_{2}$ asymptote is also observed around the energy values of $20,300 \sim 20,400 \mathrm{~cm}^{-1}(58 \mathrm{kcal} / \mathrm{mol})$. The energies higher than the peak at around $28,000 \mathrm{~cm}^{-1}$ correspond to geometries in the repulsive region where any of the inter-atomic distances are short.

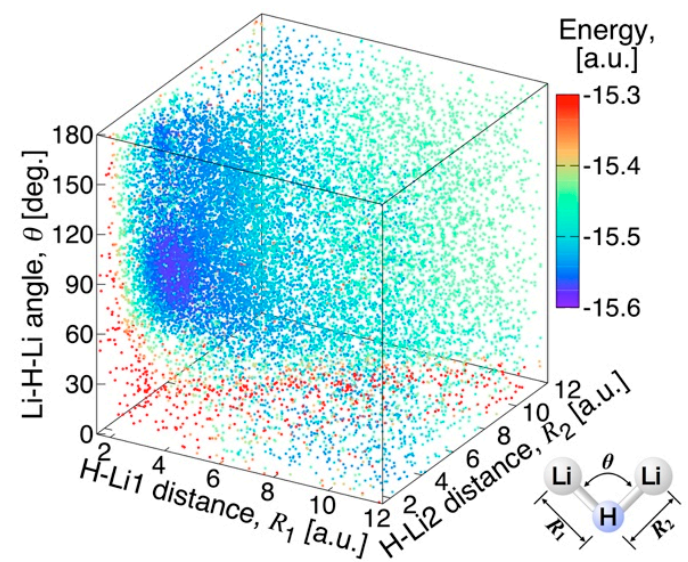

Figure 1. Distribution of the ab initio points for the ground state of $\mathrm{Li}_{2} \mathrm{H}$.

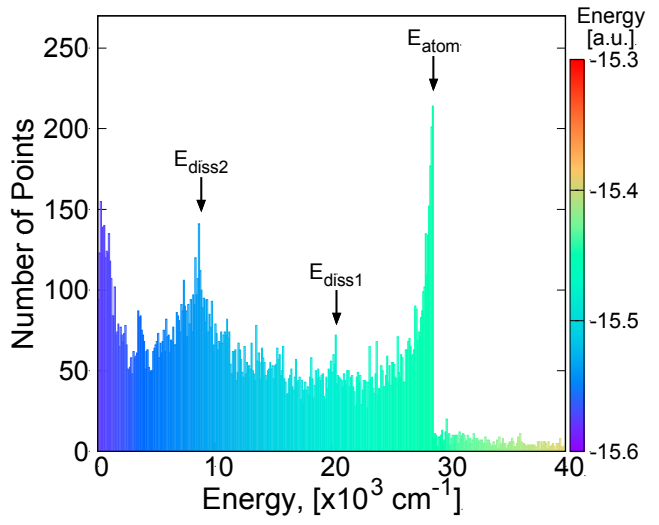

Figure 2. Population histogram of the calculation points over electronic energies. $E_{\text {atom, }}, E_{\text {diss } 1}$, and $\mathrm{E}_{\text {diss } 2}$ correspond to the atomization energy, dissociation energies in the $\mathrm{Li}_{2} \mathrm{H} \rightarrow \mathrm{Li}_{2}+\mathrm{H}$ and $\mathrm{Li}_{2} \mathrm{H} \rightarrow$ $\mathrm{Li}+\mathrm{LiH}$, respectively (See text). 
A fitting function of the potential surface of $\mathrm{Li}_{2} \mathrm{H}$ of the form of Equation (2) was then generated from this grid of MRCI energies using the MSA software (see Ref. [21]). We used $k=12$ for the highest order of the polynomial of the fitting function, which was found to be optimal, as it leads to a small fitting error for the global PES. The obtained fitting function is a linear combination of 252 monomial basis functions. A Fortran routine for the PES is provided in the Supplementary Materials.

The quality of the present fitting function is examined in Figures 3-6. The fitting error distribution in the coordinate space is shown in Figure 3, and in the energy domain in Figure 4. In these figures, the fitting error is defined by the difference between the energy values from the fitting function and from the $a b$ initio calculation. The relative fitting error is obtained from the latter when divided by the ab initio energy values. The root mean square (RMS) of each energy interval, and the cumulative RMS are also shown in Figure 4. The present error is smaller than $0.5 \%$ near the equilibrium geometry as seen in Figure 3, and the RMS of the energy intervals below $2500 \mathrm{~cm}^{-1}$ is less than $44 \mathrm{~cm}^{-1}$. This indicates that the present fitting function represents well the PES around the global minimum. More precisely, the deviation from the MRCI values is about 0.0001 Hartree $\left(22 \mathrm{~cm}^{-1}\right)$ at the minimum energy and 0.0017 a.u. and 0.77 degrees for the $\mathrm{Li}-\mathrm{H}$ bond length and $\angle(\mathrm{Li}-\mathrm{H}-\mathrm{Li})$ angle, respectively (see Table 1). The rotational constants in GHz determined from the present MSA fitting, $\left(\mathrm{A}_{\mathrm{e}}, \mathrm{B}_{\mathrm{e}}, \mathrm{C}_{\mathrm{e}}\right)=$ $(22.28,386.90,23.64)$, compare very well with the MRCI values $\left(A_{e}, B_{e}, C_{e}\right)=(22.06,392.82,23.37)$.

The percentage error of the atomic asymptote is also small, where the two $\mathrm{Li}-\mathrm{H}$ bond lengths are large and the $\angle(\mathrm{Li}-\mathrm{H}-\mathrm{Li})$ angle is large, as can be seen in Figure 3. Figure 4 shows that the RMS in the energy intervals in the range from $28,000 \mathrm{~cm}^{-1}$ to $29,000 \mathrm{~cm}^{-1}$, which is close to the atomization energy limit, is as low as $60 \mathrm{~cm}^{-1}$ on average, although the number of calculation points in this energy range is larger. The calculated points with larger errors are concentrated mostly on the geometries having large angles of $\mathrm{Li}-\mathrm{H}-\mathrm{Li}$ and intermediate $\mathrm{Li}-\mathrm{H}$ bond lengths, as shown in Figure 3. Correspondingly, most of the RMS is cumulated in the energy range from $5000 \mathrm{~cm}^{-1}$ to $25,000 \mathrm{~cm}^{-1}$, as seen in the plot of cumulated RMS in Figure 4. The RMS averaged for all the calculation points is $154 \mathrm{~cm}^{-1}$. To visualize the quality of the MSA fitting over a large energy domain, we plotted a section of the PES corresponding to the symmetric stretch (Figure 5) and to the antisymmetric stretch (Figure 6), where the $\mathrm{Li}-\mathrm{H}-\mathrm{Li}$ angle was fixed at 93.7 degrees. As can be seen from these plots, the analytical function perfectly matches the ab initio values, except in the middle range part of the symmetric stretch potential curve corresponding to energies in the $18,000-27,000 \mathrm{~cm}^{-1}$ energy range, where the deviation can locally be as large as $1000 \mathrm{~cm}^{-1}$.

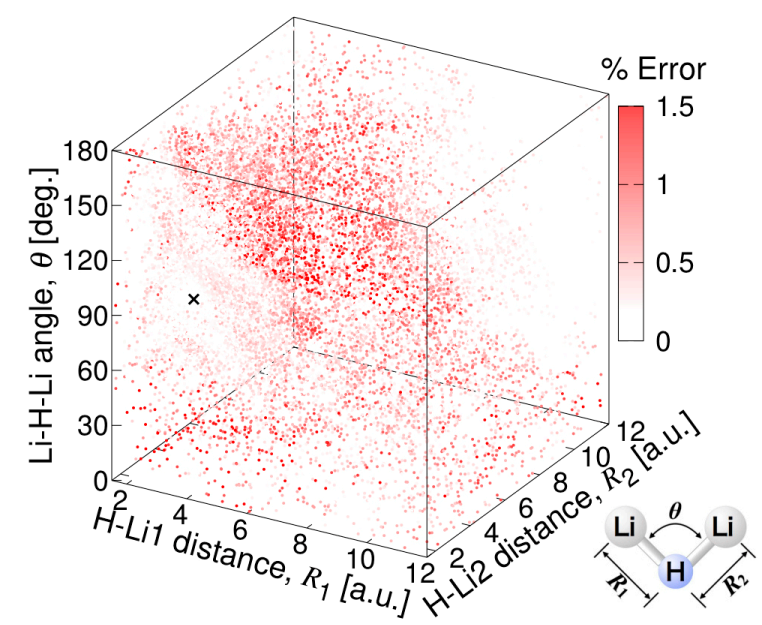

Figure 3. Fitting error distribution of the global analytical PES of $\mathrm{Li}_{2} \mathrm{H}$ in the coordinate space ( $\times$ : equilibrium geometry). 


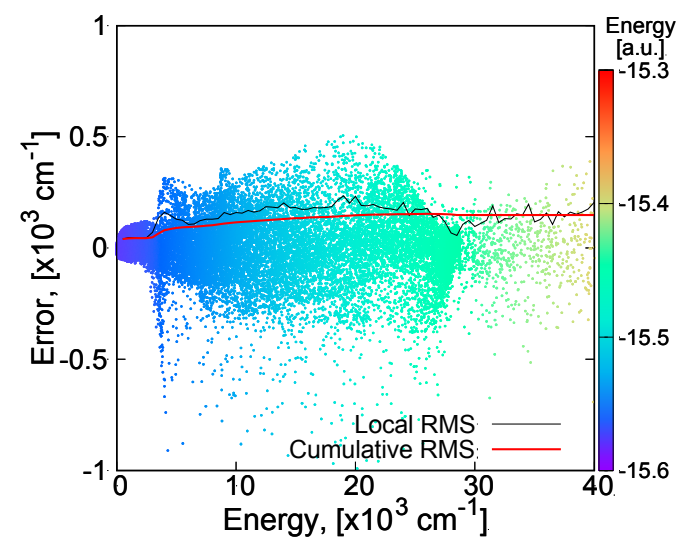

Figure 4. Fitting error distribution of the global analytical PES of $\mathrm{Li}_{2} \mathrm{H}$ in the energy domain (in $\mathrm{cm}^{-1}$ ).

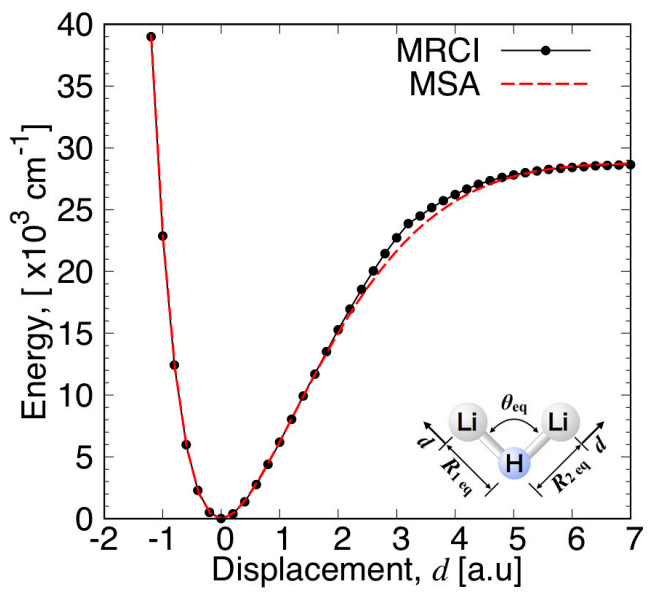

Figure 5. Potential energy curve for the symmetric stretch of $\mathrm{Li}_{2} \mathrm{H}$ at the equilibrium angle.

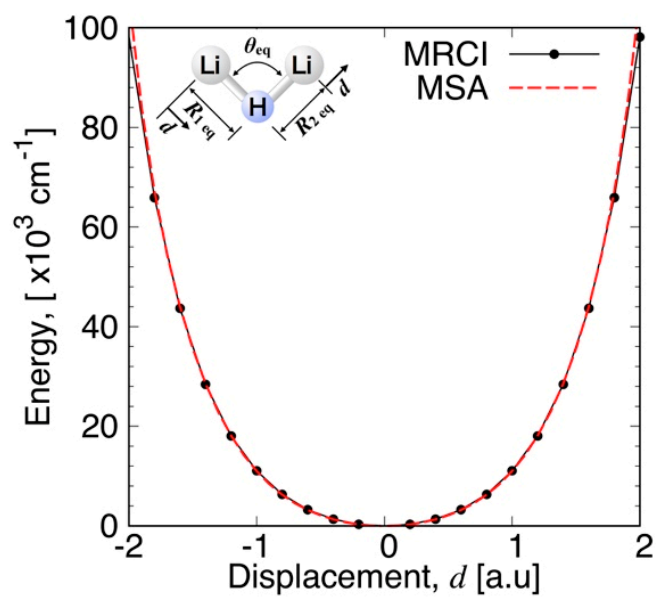

Figure 6. Potential energy curve for the antisymmetric stretch of $\mathrm{Li}_{2} \mathrm{H}$ at the equilibrium angle. 


\subsubsection{Features of the Present Potential Energy Surface}

The energy contours in Figure 7 show the potential surface energy when the Li atom is moving around $\mathrm{LiH}$, the distance of which is fixed at the equilibrium distance 3.235 a.u. in the $\mathrm{Li}_{2} \mathrm{H}$ complex. Similarly, the energy contours when the $\mathrm{H}$ atom is moving around $\mathrm{Li}_{2}$ at the distance of 4.690 a.u. are shown in Figure 8. Minimum energy points appearing in these figures-at $(x, y)=(0.000,2.228)$ a.u. in Figure 8 , and $(x, y)=(1.783,3.230)$ a.u. in Figure 7 . Energy contours when the Li atom moves around a fixed $\mathrm{Li}-\mathrm{H}$ distance with $\mathrm{r}(\mathrm{Li}-\mathrm{H})=3.235$ a.u. The center of mass of $\mathrm{LiH}$ is at the origin. The energy contours are equally spaced by $0.1 \mathrm{eV}$, starting at the ground state minimum.-correspond to the global minimum energy point with the $\mathrm{Li}-\mathrm{H}$ distance of 3.235 a.u. and the $\mathrm{Li}-\mathrm{H}-\mathrm{Li}$ angle of 92.93 degrees. These contours confirm that the present potential energy surface is fitted smoothly. It can be seen from theses energy contours that the formation of the bent $\mathrm{Li}_{2} \mathrm{H}$ complex from the insertion of $\mathrm{H}$ into $\mathrm{Li}_{2}$ or from the insertion of $\mathrm{Li}$ into $\mathrm{LiH}$ proceeds via a barrier-less mechanism, leading to large rate constants for both reactions at low temperature. The leading forces are of different nature in each channel: the major contribution in the attractive long-range potential in the $\mathrm{Li}+\mathrm{LiH}$ channel is a permanent dipole-quadrupole interaction, whereas it is a permanent quadrupole-quadrupole interaction in the $\mathrm{Li}_{2}+\mathrm{H}$ channel.

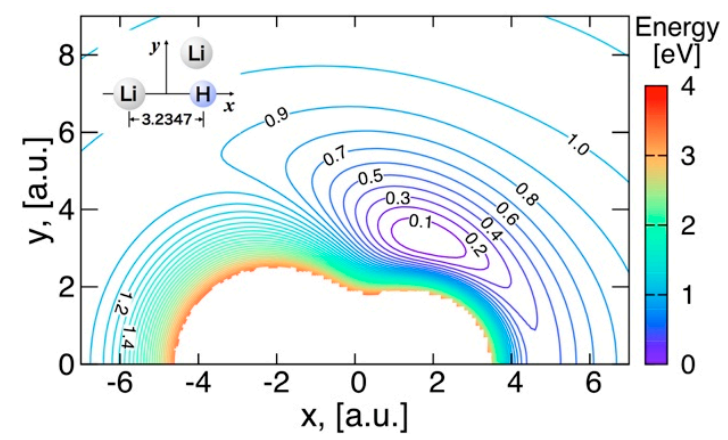

Figure 7. Energy contours when the $\mathrm{Li}$ atom moves around a fixed $\mathrm{Li}-\mathrm{H}$ distance with $\mathrm{r}(\mathrm{Li}-\mathrm{H})=$ 3.235 a.u. The center of mass of $\mathrm{LiH}$ is at the origin. The energy contours are equally spaced by $0.1 \mathrm{eV}$, starting at the ground state minimum.

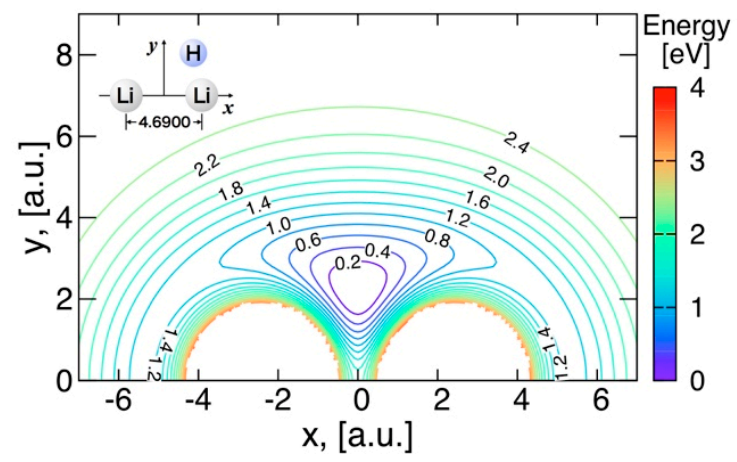

Figure 8. Energy contours when the $\mathrm{H}$ atom moves around a fixed $\mathrm{Li}-\mathrm{Li}$ distance with $\mathrm{r}(\mathrm{Li}-\mathrm{Li})=$ 4.690 a.u. The center of mass of $\mathrm{Li}_{2}$ is at the origin. The energy contours are equally spaced by $0.2 \mathrm{eV}$, starting at the ground state minimum.

The energy contours of the present PES for Li-H-Li linear configuration are shown in Figure 9. The minimum energy of $0.4168 \mathrm{eV}\left(3362 \mathrm{~cm}^{-1}\right)$ is obtained at the $\mathrm{Li}-\mathrm{H}$ bond length of $3.137 \mathrm{a} . \mathrm{u}$. This is in good agreement with the 3.172 a.u. value reported by Song et al. [13]. This linear minimum actually corresponds to a saddle point of the full PES, connecting two equivalent bent equilibrium geometries of $\mathrm{Li}_{2} \mathrm{H}$. The height of the barrier to linearity will be discussed below. The asymptotic energy value of the $\mathrm{LiH}+\mathrm{Li}$ limit along the MEP is about $1.159 \mathrm{eV}(26.7 \mathrm{kcal} / \mathrm{mol})$ for the $\mathrm{Li}-\mathrm{H}$ bond length of 2.914 a.u., which is calculated as the minimum energy when one of the LiH-Li lengths is fixed at 
45 a.u. This value is in reasonable agreement with the dissociation energy of $25.24 \mathrm{kcal} / \mathrm{mol}$ for the reaction $\mathrm{Li}_{2} \mathrm{H} \rightarrow \mathrm{LiH}+\mathrm{Li}$ obtained from MRCI calculations, as shown in Table 1. Another interesting feature of Figure 9 is that the formation of the linear saddle point is barrier-less, so that the formation of the bent $\mathrm{Li}_{2} \mathrm{H}$ complex can proceed through this saddle point.

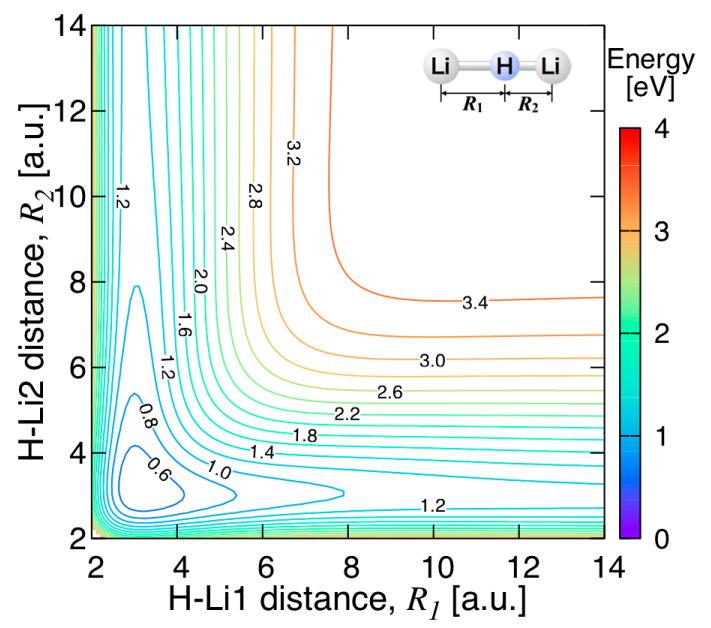

Figure 9. Energy contours for the $\mathrm{Li}-\mathrm{H}-\mathrm{Li}$ linear configuration. The energy contours are equally spaced by $0.2 \mathrm{eV}$, starting at the ground state minimum.

Figure 10 shows the energy contours of the present PES for the $\mathrm{Li}-\mathrm{Li}-\mathrm{H}$ linear configuration. There exists a local minimum energy point at the $\mathrm{Li}-\mathrm{H}$ bond lengths of $3.050 \mathrm{a} . \mathrm{u}$. and the $\mathrm{Li}-\mathrm{Li}$ bond lengths of 6.116 a.u., lying at $0.8902 \mathrm{eV}(20.52 \mathrm{kcal} / \mathrm{mol})$ above the global minimum energy. As in Figure 9, this local minimum is a $\mathrm{C}_{\infty \mathrm{v}}$ saddle point of the full PES, connecting two equivalent bent geometries, through an energy barrier of less than $0.9 \mathrm{eV}$. This agrees well with the results of Song et al. [13], the local minimum energy value of which is $22.15 \mathrm{kcal} / \mathrm{mol}$ at the $\mathrm{Li}-\mathrm{H}$ bond lengths of $3.079 \mathrm{a} . \mathrm{u}$. and the $\mathrm{Li}-\mathrm{Li}$ bond lengths of 5.960 a.u. The asymptotic energy along the $\mathrm{MEP}$ at the $\mathrm{Li}_{2}+\mathrm{H}$ limit is about $2.449 \mathrm{eV}(56.44 \mathrm{kcal} / \mathrm{mol})$, and at the $\mathrm{LiH}+\mathrm{Li}$ limit about $1.159 \mathrm{eV}(26.71 \mathrm{kcal} / \mathrm{mol})$, showing a very good agreement with the MRCI dissociation energies (see Table 1). Contrary to the linear barrier-less $\mathrm{Li}+\mathrm{LiH}$ reaction, the linear approach of $\mathrm{H}$ towards $\mathrm{Li}_{2}$ is unfavorable at low collision energies due to a small energy barrier of less than $0.15 \mathrm{eV}$, as can be seen from the energy contours of Figure 10.

Figure 11 shows the energy contours of the PES for the $\mathrm{C}_{2 \mathrm{v}}$ insertion of $\mathrm{H}$ into $\mathrm{Li}-\mathrm{Li}$. MEPs from the $\mathrm{Li}_{2}+\mathrm{H}$ asymptote to the linearity barrier of $\mathrm{Li}_{2} \mathrm{H}$ obtained at the MRCI level and with the fitted PES are also compared in this figure. The agreement between the two paths is very good, with only slight differences for large Li-H-Li angles ( $\theta>150$ degrees). Please note that the energy values at the low $\mathrm{Li}-\mathrm{H}-\mathrm{Li}$ angles in the MSA fitting results are extrapolated values of the fitting function, because the $\mathrm{Li}-\mathrm{H}$ distances for these angles are out of the range of the MRCI database used for the fitting. This can be the cause of the underestimation of the energy of the fitted PES at the $\mathrm{Li}_{2}+\mathrm{H}$ asymptote. The highest value of the energy along the MEP obtained by the MSA fitting is $2.529 \mathrm{eV}$ $\left(20396 \mathrm{~cm}^{-1}\right.$ or $\left.58.28 \mathrm{kcal} / \mathrm{mol}\right)$. The energy barrier to linearity of the PES obtained by the MSA fitting is found at the saddle point of Figure 11 at a $\mathrm{Li}-\mathrm{H}$ bond length of 3.1367 a.u. and a $\angle(\mathrm{Li}-\mathrm{H}-\mathrm{Li})$ angle of 180.0 degrees with an energy of $0.4168 \mathrm{eV}\left(3362 \mathrm{~cm}^{-1}\right.$ or $\left.9.06 \mathrm{kcal} / \mathrm{mol}\right)$. This value is in good agreement with the value of $10.6 \mathrm{kcal} / \mathrm{mol}$ found in Ref. [13]. 


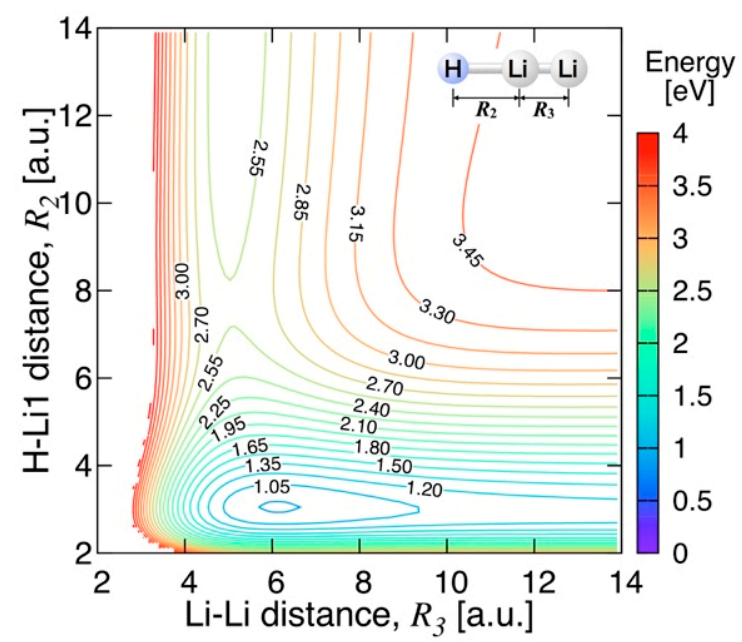

Figure 10. Energy contours for the $\mathrm{Li}-\mathrm{Li}-\mathrm{H}$ linear configuration. The energy contours are equally spaced by $0.15 \mathrm{eV}$, starting at the ground state minimum.

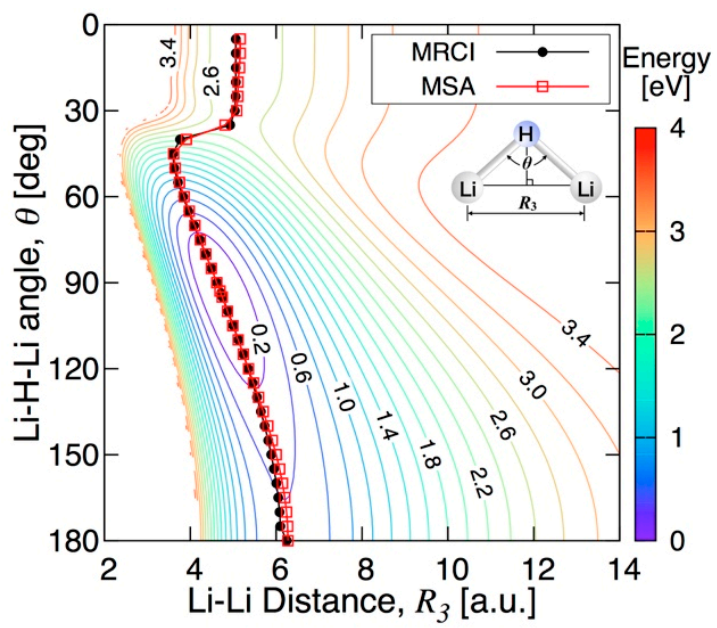

Figure 11. Energy contours of the insertion of $\mathrm{H}$ into $\mathrm{Li}_{2}$ in $\mathrm{C}_{2 \mathrm{v}}$ symmetry. The energy contours are equally spaced by $0.2 \mathrm{eV}$, starting at the ground state minimum.

\subsection{Vibrational Levels}

The vibrational levels of $\mathrm{Li}_{2} \mathrm{H}$ are calculated from the present potential energy surface by using the MULTIMODE program [22]. To avoid singularity problems in the MULTIMODE calculations, which occur when the molecular configuration is linear, the vibrational levels are calculated for energy levels lower than the linearity barrier. For a better accuracy of the low-lying vibrational levels, a local MSA fitting for the energies below the linearity barrier was carried out. The local MSA fitting uses 2462 points under the energy of $12,000 \mathrm{~cm}^{-1}$, which are taken from the points used for the global PES fitting in the parameter ranges of $40<\theta<180$ degrees for the $\mathrm{Li}-\mathrm{H}-\mathrm{Li}$ angle, $2.7<\mathrm{r}(\mathrm{Li}-\mathrm{Li})<6.0$ a.u. for the $\mathrm{Li}-\mathrm{Li}$ distance, $2.1<\mathrm{r}(\mathrm{Li}-\mathrm{H})<5.72$ a.u. for the $\mathrm{Li}-\mathrm{H}$ distance, and $4.3<\mathrm{r}(\mathrm{Li} 1-\mathrm{H})+\mathrm{r}\left(\mathrm{Li}_{2}-\mathrm{H}\right)<9.8$ a.u. for the sum of two Li-H distances. The RMS of the local fitting is $9 \mathrm{~cm}^{-1}$, while that of the global fitting for the points below the linearity barrier is $47 \mathrm{~cm}^{-1}$. In the MULTIMODE V-CI calculations, the number of basis functions is set to 28 for the bending mode, and 12 for the stretching modes. The Gaussian points for integrations are set to 20 . The maximum quantum numbers considered in the one-, two- and three-mode excitations are taken to be 20 for the bending mode and 8 for the stretching modes. With these parameters, 18 vibrational levels (including the ground $(0,0,0)$ level) are converged under the energy of $3362 \mathrm{~cm}^{-1}$. 
In Table 3 we report the harmonic $\left(\omega_{i}\right)$ and anharmonic $\left(v_{i}\right)$ frequencies of the normal modes calculated with the Molpro VCI routine [33] using the grid surface calculated at MRCI and UCCSD(T)-F12 levels on one hand, and from MULTIMODE V-CI with the MSA local and global fits (hereafter MM/MSA) on the other hand. The harmonic frequencies (in $\mathrm{cm}^{-1}$ ) of the bending, symmetric stretching and antisymmetric stretching modes are noted $\omega_{1}, \omega_{2}$ and $\omega_{3}$ respectively.

First, it can be seen that the frequencies at the MRCI level are systematically red-shifted compared to those at UCCSD(T)-F12 level (i.e., they are larger), with a difference lying within a range of $4-10 \mathrm{~cm}^{-1}$ for harmonic frequencies, and up to $26 \mathrm{~cm}^{-1}$ difference for the anharmonic symmetric stretching. This shows that even two accurate high-level ab initio methods can lead to errors on frequencies that are much greater than the $1 \mathrm{~cm}^{-1}$ spectroscopic accuracy. One may expect even larger differences for higher-lying vibrational energy levels. Second, the MM/MSA calculations using the local fit of the PES are in excellent agreement with the MRCI VCI calculations as far as the harmonic frequencies are concerned (less than $3 \mathrm{~cm}^{-1}$ error), much better than those with the global PES (up to $23 \mathrm{~cm}^{-1}$ error). The same comparison for anharmonic frequencies showed larger errors (up to $35 \mathrm{~cm}^{-1}$, up to $4 \%$ error), although the comparison is biased since the number of basis functions and maximum quantum numbers in the mode excitations is different in the MULTIMODE and MOLPRO V-CI calculations. In any case, the MM/MSA anharmonic frequencies are lowered by about $5 \%$ for the bending and the symmetric stretching mode, and $8 \%$ for the antisymmetric stretching mode with both global and local PESs. Similar trends are observed with MOLPRO VCI calculations at UCCSD(T)-F12 level, and a somewhat more pronounced lowering (about 9\%) at MRCI level.

The vibrational quantum numbers and the vibrational energy levels obtained with MULTIMODE are summarized in Table 4. Here, only the vibrational quantum numbers corresponding to the major contribution to the vibrational energy of interest are shown. The calculated zero-point energy is $12,22.8 \mathrm{~cm}^{-1}$, and therefore, the linearity barrier measurement from the zero-point energy is $2135 \mathrm{~cm}^{-1}$. Under the linearity barrier, 18 vibrational levels are obtained. These energy levels are also schematically drawn in the Figure 12, where one can see that the energy gaps between the one-mode excited levels in red lines are slightly reduced for higher levels. Since the one-mode excited levels of symmetric and antisymmetric modes are similar to each other, their two-mode excited levels in blue with bending modes are also similarly distributed. However, some of the energy gaps between adjacent quantum number levels vary irregularly, due to the coupling of the corresponding vibrational states with other states. We report in Table 5 the first three sets of dominant quantum numbers with their coefficients. As can be seen in this table, the close absolute values of coefficients at the energy of $1876.42 \mathrm{~cm}^{-1}$ and $1966.69 \mathrm{~cm}^{-1}$ implies that the vibrational states $(0,0,2)$ and $(0,2,0)$ are strongly coupled each other. Although one-mode excited levels of bending mode are not coupled very much with the other excited levels, two-mode excited levels show weak but non-negligible couplings. The bending-symmetric two-mode excited levels are weakly coupled with other two-mode excited levels, and the bending-antisymmetric two-mode excited levels are weakly coupled with three-mode excited levels. These results indicate that even at relatively low vibrational energies below the barrier to linearity, some vibrational states are strongly correlated, and couplings between different modes must be considered in order to get accurate vibrational energy levels. 
Table 3. Calculated harmonic $\left(\omega_{\mathrm{i}}\right)$ and anharmonic $\left(v_{\mathrm{i}}\right)$ vibrational frequencies of the ground electronic state of the $\mathrm{Li}_{2} \mathrm{H}$ complex using MULTIMODE on the local and global PESs and the VCI routine of MOLPRO at MRCI and UCCSD(T)-F12 levels $\left(\omega_{1}, v_{1}\right.$ : bending; $\omega_{2}, v_{2}$ : symmetric stretching; $\omega_{3}, v_{3}$ : antisymmetric stretching).

\begin{tabular}{|c|c|c|c|c|c|c|}
\hline & \multicolumn{6}{|c|}{ Vibrational Frequency } \\
\hline & \multicolumn{3}{|c|}{ Harmonic } & \multicolumn{3}{|c|}{ Anharmonic } \\
\hline & $\underset{\left[\mathrm{cm}^{-1}\right]}{\omega_{1}}$ & $\begin{array}{c}\omega_{2} \\
{\left[\mathrm{~cm}^{-1}\right]}\end{array}$ & $\begin{array}{c}\omega_{3} \\
{\left[\mathrm{~cm}^{-1}\right]}\end{array}$ & $\underset{\left[\mathrm{cm}^{-1}\right]}{v_{1}}$ & $\begin{array}{c}v_{2} \\
{\left[\mathrm{~cm}^{-1}\right]}\end{array}$ & $\begin{array}{c}v_{3} \\
{\left[\mathrm{~cm}^{-1}\right]}\end{array}$ \\
\hline MULTIMODE (Global PES) ${ }^{a}$ & 395.46 & 1039.11 & 1056.73 & 376.92 & 983.87 & 971.79 \\
\hline MULTIMODE (Local PES) ${ }^{b}$ & 379.73 & 1031.62 & 1079.89 & 365.00 & 982.48 & 989.33 \\
\hline Molpro (VCI, MRCI) ${ }^{\mathrm{c}}$ & 380.07 & 1034.22 & 1079.41 & 345.29 & 947.18 & 978.44 \\
\hline Molpro (VCI, UCCSD(T)-F12) d & 376.12 & 1023.60 & 1071.50 & 362.22 & 973.49 & 981.20 \\
\hline
\end{tabular}

Table 4. MULTIMODE V-CI energies $\left(\mathrm{cm}^{-1}\right)$ of the low-lying vibrational energy levels (below the barrier to linearity) relative to the zero-point energy of nonrotating $\mathrm{Li}_{2} \mathrm{H}$, using the local PES (see text).

\begin{tabular}{|c|c|c|c|c|c|c|c|c|c|}
\hline \multicolumn{5}{|c|}{ Levels of $A_{1}$ Symmetry } & \multicolumn{5}{|c|}{ Levels of $B_{2}$ Symmetry } \\
\hline$i$ & $\mathbf{v}_{1}$ & $\mathbf{v}_{2}$ & $\mathbf{v}_{3}$ & & $i$ & $\mathbf{v}_{1}$ & $\mathbf{v}_{2}$ & $\mathbf{v}_{3}$ & \\
\hline 1 & 1 & 0 & 0 & 365.00 & 4 & 0 & 0 & 1 & 989.33 \\
\hline 2 & 2 & 0 & 0 & 724.46 & 7 & 1 & 0 & 1 & 1347.74 \\
\hline 3 & 0 & 1 & 0 & 982.48 & 10 & 2 & 0 & 1 & 1699.78 \\
\hline 5 & 3 & 0 & 0 & 1077.97 & 13 & 0 & 1 & 1 & 1945.16 \\
\hline 6 & 1 & 1 & 0 & 1333.73 & 16 & 3 & 0 & 1 & 2044.91 \\
\hline 8 & 4 & 0 & 0 & 1425.01 & \multirow{7}{*}{\multicolumn{5}{|c|}{ Zero point energy: $1222.76 \mathrm{~cm}^{-1}$}} \\
\hline 9 & 2 & 1 & 0 & 1678.27 & & & & & \\
\hline 11 & 5 & 0 & 0 & 1765.03 & & & & & \\
\hline 12 & 0 & 0 & 2 & 1876.42 & & & & & \\
\hline 14 & 0 & 2 & 0 & 1966.69 & & & & & \\
\hline 15 & 3 & 1 & 0 & 2015.30 & & & & & \\
\hline 17 & 6 & 0 & 0 & 2097.23 & & & & & \\
\hline
\end{tabular}

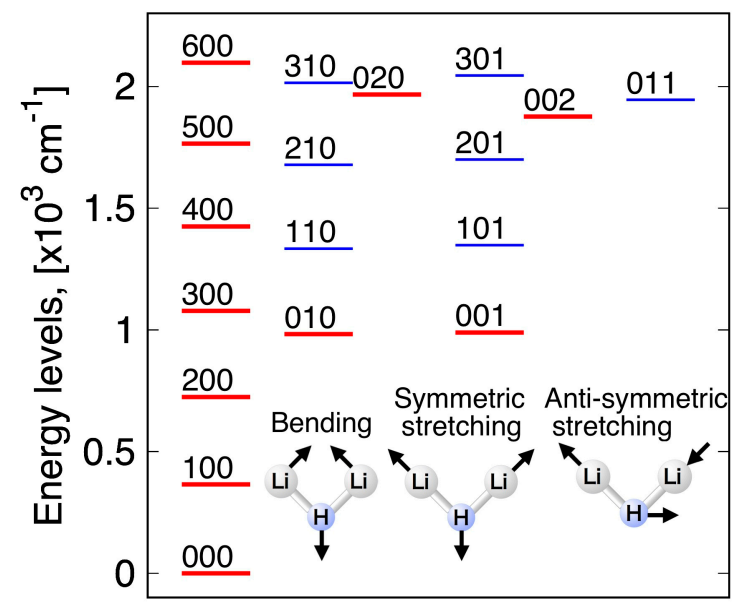

Figure 12. Energy diagram of some low-lying vibrational energy levels $\left(v_{1} v_{2} v_{3}\right)$ of the ground electronic state of the $\mathrm{Li}_{2} \mathrm{H}$ complex. Levels underlined in red (blue) are one-mode (resp. two-mode) energy levels. 
Table 5. Coupling of the vibrational states of the ground electronic state of the $\mathrm{Li}_{2} \mathrm{H}$ complex. The more strongly coupled states are highlighted in gray.

\begin{tabular}{ccccccccccccc}
\hline Energy & \multicolumn{4}{c}{ First } & \multicolumn{4}{c}{ Second } & \multicolumn{3}{c}{ Third } \\
\cline { 2 - 12 } $\mathbf{[ c m}^{-\mathbf{1}}$ ] & $\mathbf{v}_{\mathbf{1}}$ & $\mathbf{v}_{\mathbf{2}}$ & $\mathbf{v}_{\mathbf{3}}$ & Coeff. & $\mathbf{v}_{\mathbf{1}}$ & $\mathbf{v}_{\mathbf{2}}$ & $\mathbf{v}_{\mathbf{3}}$ & Coeff. & $\mathbf{v}_{\mathbf{1}}$ & $\mathbf{v}_{\mathbf{2}}$ & $\mathbf{v}_{\mathbf{3}}$ & Coeff. \\
\hline 365.00 & 1 & 0 & 0 & 0.9978 & 1 & 1 & 2 & -0.0515 & 2 & 2 & 0 & 0.0197 \\
724.46 & 2 & 0 & 0 & 0.9961 & 2 & 1 & 2 & -0.0513 & 0 & 1 & 0 & -0.0335 \\
982.48 & 0 & 1 & 0 & -0.9746 & 0 & 0 & 2 & 0.1509 & 1 & 1 & 0 & -0.1277 \\
989.33 & 0 & 0 & 1 & 0.9697 & 0 & 1 & 1 & 0.2111 & 0 & 1 & 3 & -0.1006 \\
1077.97 & 3 & 0 & 0 & 0.9926 & 1 & 1 & 0 & 0.0586 & 3 & 1 & 2 & -0.0507 \\
1333.73 & 1 & 1 & 0 & 0.9520 & 2 & 1 & 0 & 0.1861 & 1 & 0 & 2 & -0.1470 \\
1347.74 & 1 & 0 & 1 & 0.9699 & 1 & 1 & 1 & 0.2024 & 1 & 1 & 3 & -0.1016 \\
1425.01 & 4 & 0 & 0 & 0.9860 & 2 & 1 & 0 & 0.0819 & 4 & 1 & 0 & -0.0653 \\
1678.27 & 2 & 1 & 0 & -0.9193 & 3 & 1 & 0 & 0.2344 & 1 & 1 & 0 & 0.1899 \\
1699.78 & 2 & 0 & 1 & 0.9697 & 2 & 1 & 1 & 0.1915 & 2 & 1 & 3 & -0.1026 \\
1765.03 & 5 & 0 & 0 & -0.9745 & 3 & 1 & 0 & -0.1018 & 5 & 1 & 0 & 0.0881 \\
1876.42 & 0 & 0 & 2 & 0.6844 & 0 & 2 & 0 & -0.5207 & 0 & 1 & 2 & 0.4024 \\
1945.16 & 0 & 1 & 1 & -0.8593 & 0 & 2 & 1 & -0.2739 & 0 & 0 & 3 & 0.2492 \\
1966.69 & 0 & 2 & 0 & -0.7742 & 0 & 0 & 2 & -0.5558 & 1 & 2 & 0 & -0.2176 \\
2015.30 & 3 & 1 & 0 & -0.8708 & 4 & 1 & 0 & -0.2767 & 2 & 1 & 0 & -0.2461 \\
2044.91 & 3 & 0 & 1 & 0.9682 & 3 & 1 & 1 & 0.1777 & 3 & 1 & 3 & -0.1033 \\
2097.23 & 6 & 0 & 0 & 0.9548 & 3 & 1 & 0 & 0.1158 & 4 & 1 & 0 & -0.1141 \\
\hline
\end{tabular}

\section{Conclusions}

A full-dimensional ab initio potential energy surface of the $\mathrm{Li}_{2} \mathrm{H}$ complex was successfully built using the monomial symmetrization approach (MSA) to fit more than 20,000 ab initio MRCI energies, including core-valence correlation effects. These effects mainly impact the geometry (lowering of bond lengths by typically $0.01 \AA$ and angles by $0.3^{\circ}$ ) and, to a lesser extent, the atomization energy (increasing by $0.3 \mathrm{kcal} \cdot \mathrm{mol}^{-1}$ ) and ionization potential (increasing by $0.7 \mathrm{kcal} \cdot \mathrm{mol}^{-1}$ ) of the $\mathrm{Li}_{2} \mathrm{H}$ complex. In some particular cases, the exclusion of the core-valence correlation may appear to give better result in comparison with the experimental data, but this would be purely fortuitous. MRCI data points randomly scattered in a wide range of the valence coordinates enabled us to fit the potential energy surface with good accuracy, not only in the neighborhood of the global minimum energy point, but also for the long-range region approaching to the atomization limit $2 \mathrm{Li}+\mathrm{H}$ but also $\mathrm{LiH}+\mathrm{Li}$ and $\mathrm{Li}_{2}+\mathrm{H}$ dissociation limits. From a local fit of this new potential energy surface, vibrational energy levels were calculated using the MULTIMODE program: 18 levels were found below the barrier to linearity of $3362 \mathrm{~cm}^{-1}$, with a maximum of 6 quanta in the bending mode. The contracting coefficients for the vibrational energy levels clearly show that some of the vibrational levels are strongly correlated already well below the barrier, and considering two- and three-mode coupling, appear to be essential to determining accurate vibrational energy levels. We hope our calculations can stimulate the determination of the experimental infrared spectrum of gaseous $\mathrm{Li}_{2} \mathrm{H}$, which is still lacking in the literature, and help assigning experimental lines. Our future goal is to assign some transition lines attributed to $\mathrm{Li}_{2} \mathrm{H}$ in the photo-ionization spectra measured by Stwalley [20], from superthermal hydrogen atoms colliding with $\mathrm{Li}$ atoms and $\mathrm{Li}_{2}$ molecules. To achieve this, higher vibrational levels than those analyzed in this work need to be calculated, as well as vibrational levels of the $\mathrm{Li}_{2} \mathrm{H}^{+}$cation.

Supplementary Materials: The supplementary materials are available online.

Author Contributions: Conceptualization, M.A.F., D.H.-R. and G.-H.J.; methodology, M.A.F. and D.H.-R.; validation, M.A.F., D.H.-R. and G.-H.J.; formal analysis, M.A.F. and D.H.-R.; investigation, M.A.F. and D.H.-R.; resources, D.H.-R. and G.-H.J.; writing-original draft preparation, M.A.F., G.-H.J. and D.H.-R.; writing-review and editing, M.A.F. and D.H.-R.; visualization, M.A.F. and D.H.-R.; supervision, D.H.-R. and G.-H.J.

Funding: This research received no external funding. 
Acknowledgments: The authors would like to thank to Joel Bowman, Department of Chemistry, Emory University, USA for providing us the MSA and MULTIMODE software, for helpful discussions and for his very kind advice.

Conflicts of Interest: The authors declare no conflict of interest.

\section{References}

1. Jeung, G.-H. Multiple ionic-covalent couplings in molecules and clusters. Chin. J. Chem. Phys. 2009, 22, 187. [CrossRef]

2. Pekeris, C.L. 1 1S, 2 1S, and 23 states of H- and of He. Phys. Rev. 1962, 126, 1470-1476. [CrossRef]

3. Sakintuna, B.; Lamari-Darkrim, F.; Hirscher, M. Metal hydride materials for solid hydrogen storage: A review. Int. J. Hydrogen Energy 2007, 32, 1121-1140. [CrossRef]

4. Siegbahn, P.; Schaefer, H.F. Potential energy surfaces for $\mathrm{H}+\mathrm{Li}_{2} \rightarrow \mathrm{LiH}+\mathrm{Li}$ ground state surface from large scale configuration interaction. J. Chem. Phys. 1975, 62, 3488-3495. [CrossRef]

5. England, W.B.; Sabelli, N.H.; Wahl, A.C. A theoretical study of $\mathrm{Li}_{2}$ H. I. Basis set and computational survey of excited states and possible reaction paths. J. Chem. Phys. 1975, 63, 4596-4605. [CrossRef]

6. Talbi, D.; Saxon, R.P. Low-lying states of $\mathrm{Li}_{3} \mathrm{H}$ : Is there an ion-pair minimum? Chem. Phys. Lett. 1989, 157, 419-425. [CrossRef]

7. Rao, B.K.; Khanna, S.N.; Jena, P. Energetics and electronic structures of hydrogenated metal clusters. Phys. Rev. B 1991, 43, 1416-1421. [CrossRef]

8. Fang, W.; You, X.; Yin, Z. A theoretical study on the low-lying electronic states of the $\mathrm{Li}_{2} \mathrm{H}$ molecule. Chem. Phys. Lett. 1995, 233, 237-242. [CrossRef]

9. Allouche, A.R.; Aubert-Frecon, M.; Spiegelmann, F. Theoretical study of the electronic structure of the low-lying states of the $\mathrm{Li}_{2} \mathrm{H}$ molecule. Can. J. Phys. 1996, 74, 194-201. [CrossRef]

10. Antoine, R.; Dugourd, P.; Rayane, D.; Allouche, A.-R.; Aubert-Frécon, M.; Broyer, M. On the optical absorption spectrum of $\mathrm{Li}_{2} \mathrm{H}$. Chem. Phys. Lett. 1996, 261, 670-676. [CrossRef]

11. Vezin, B.; Dugourd, P.; Rayane, D.; Labastie, P.; Broyer, M. First observation of an excited state of $\operatorname{Li}_{2} \mathrm{H}_{\text {. }}$ Chem. Phys. Lett. 1993, 202, 209-215. [CrossRef]

12. Maniero, A.M.; Acioli, P.H.; e Silva, G.M.; Gargano, R. Theoretical calculations of a new potential energy surface for the $\mathrm{H}+\mathrm{Li}_{2}$ reaction. Chem. Phys. Lett. 2010, 490, 123-126. [CrossRef]

13. Song, Y.-Z.; Li, Y.-Q.; Gao, S.-B.; Meng, Q.-T. Accurate ab initio-based DMBE potential energy surface for $\mathrm{HLi}_{2}\left(\mathrm{X}^{2} \mathrm{~A}^{\prime}\right)$ via scaling of the external correlation. Eur. Phys. J. D 2014, 68, 3. [CrossRef]

14. Yuan, $\mathrm{M}$.; $\mathrm{Li}, \mathrm{W} . ;$ Chen, $\mathrm{M}$. Global $\mathrm{X}^{2} \mathrm{~A}^{\prime}$ potential energy surface of $\mathrm{Li}_{2} \mathrm{H}$ and quantum dynamics of $\mathrm{H}+\mathrm{Li}_{2}$ $\left(\mathrm{X}^{1} \Sigma_{\mathrm{g}}{ }^{+}\right) \rightarrow \mathrm{Li}+\mathrm{LiH}\left(\mathrm{X}^{1} \Sigma^{+}\right)$reaction. Int. J. Quantum Chem. 2017, 117, e25380. [CrossRef]

15. Gao, S.; Zhang, J.; Song, Y.; Meng, Q.-T. Cross sections for vibrational inhibition at low collision energies for the reaction $\mathrm{H}+\mathrm{Li}_{2}\left({ }^{1} \mathrm{X} \Sigma_{\mathrm{g}}{ }^{+}\right) \rightarrow \mathrm{Li}+\mathrm{LiH}\left(\mathrm{X}^{1} \Sigma_{\mathrm{g}}{ }^{+}\right)$. Eur. Phys. J. D 2015, 69, 111. [CrossRef]

16. Zhu, Z.; Dong, B.; Li, W. Quantum wave packet dynamics of the $\mathrm{H}+\mathrm{Li}_{2}$ reaction at state-to-state level of theory. Comput. Theor. Chem. 2017, 1115, 248-252. [CrossRef]

17. Gao, S.; Zhang, L.; Song, Y.; Meng, Q. Coriolis coupling effects in the $\mathrm{H}+\mathrm{Li}_{2}\left({ }^{1} \mathrm{X} \Sigma_{\mathrm{g}}{ }^{+}\right) \rightarrow \mathrm{LiH}\left(\mathrm{X}^{1} \Sigma_{\mathrm{g}}{ }^{+}\right)+\mathrm{Li}$ reaction: A time-dependent wave packet investigation. Chem. Phys. Lett. 2016, 651, 233-237. [CrossRef]

18. Vila, H.V.R.; Ribeiro, L.A.; de Macedo, L.G.M.; Gargano, R. On the angular distribution of the $\mathrm{H}+\mathrm{Li}_{2}$ cross sections: A converged time-independent quantum scattering study. Sci. Rep. 2018, 8, 1044. [CrossRef]

19. Wu, C.H.; Ihle, H.R. Binding energies of $\mathrm{Li}_{2} \mathrm{H}$ and $\mathrm{Li}_{2} \mathrm{H}^{+}$and the ionization potential of $\mathrm{Li}_{2} \mathrm{H}$. J. Chem. Phys. 1977, 66, 4356-4359. [CrossRef]

20. Crooks, J.B.; Way, K.R.; Yang, S.-C.; Wu, C.-Y.R.; Stwalley, W.C. Photon and positive ion production from collisions of superthermal hydrogen atoms with lithium atoms and molecules. J. Chem. Phys. 1978, 69, 490-491. [CrossRef]

21. Xie, Z.; Bowman, J.M. Permutationally invariant polynomial basis for molecular energy surface fitting via monomial symmetrization. J. Chem. Theory Comput. 2010, 6, 26-34. [CrossRef] [PubMed]

22. Bowman, J.M.; Carter, S.; Huang, X. MULTIMODE: A code to calculate rovibrational energies of polyatomic molecules. Int. Rev. Phys. Chem. 2003, 22, 533-549. [CrossRef]

23. Rosmus, P.; Meyer, W. Spectroscopic constants and the dipole moment functions for the ${ }^{1} \Sigma^{+}$ground state of NaLi. J. Chem. Phys. 1976, 65, 492-493. [CrossRef] 
24. Jeung, G.H.; Malrieu, J.P.; Daudey, J.P. Inclusion of core-valence correlation effects in pseudopotential calculations. I. Alkali atoms and diatoms. J. Chem. Phys. 1982, 77, 3571-3577. [CrossRef]

25. Jeung, G.H.; Daudey, J.P.; Malrieu, J.P. Inclusion of core-valence correlation effects in pseudopotential calculations. II. $\mathrm{K}_{2}$ and $\mathrm{KH}$ lowest $\Sigma^{+}$potential curves from valence-correlated wavefunctions. J. Phys. B At. Mol. Phys. 1983, 16, 699. [CrossRef]

26. Yiannopoulou, A.; Jeung, G.-H.; Park, S.J.; Lee, H.S.; Lee, Y.S. Undulations of the potential-energy curves for highly excited electronic states in diatomic molecules related to the atomic orbital undulations. Phys. Rev. A 1999, 59, 1178-1186. [CrossRef]

27. Prascher, B.P.; Woon, D.E.; Peterson, K.A.; Dunning, T.H.; Wilson, A.K. Gaussian basis sets for use in correlated molecular calculations. VII. Valence, core-valence, and scalar relativistic basis sets for $\mathrm{Li}, \mathrm{Be}, \mathrm{Na}$, and Mg. Theor. Chem. Acc. 2011, 128, 69-82. [CrossRef]

28. Werner, H.-J.; Knowles, P.J.; Knizia, G.; Manby, F.R.; Schütz, M.; Celani, P.; Korona, T.; Lindh, R.; Mitrushenkov, A.; Rauhut, G.; et al. MOLPRO, a Package of ab Initio Programs, Version 2012.1. 2012. Available online: http:/ / www.molpro.net/ (accessed on 21 November 2018).

29. Carter, S.; Bowman, J.M. The adiabatic rotation approximation for rovibrational energies of many-mode systems: Description and tests of the method. J. Chem. Phys. 1998, 108, 4397-4404. [CrossRef]

30. Kim, S.K.; Herschbach, D.R. Angular momentum disposal in atom exchange reactions. Faraday Discuss. Chem. Soc. 1987, 84, 159-169. [CrossRef]

31. Verma, K.K.; Koch, M.E.; Stwalley, W.C. Observation of levels near dissociation in the $X^{1} \Sigma_{\mathrm{g}}{ }^{+} \mathrm{State}$ of ${ }^{7} \mathrm{Li}_{2}$. J. Chem. Phys. 1983, 78, 3614-3622. [CrossRef]

32. Stwalley, W.C.; Zemke, W.T. Spectroscopy and structure of the Lithium Hydride diatomic molecules and ions. J. Phys. Chem. Ref. Data 1993, 22, 87-112. [CrossRef]

33. Neff, M.; Rauhut, G. Toward large scale vibrational configuration interaction calculations. J. Chem. Phys. 2009, 131, 124129. [CrossRef] [PubMed]

Sample Availability: Not available.

(C) 2018 by the authors. Licensee MDPI, Basel, Switzerland. This article is an open access article distributed under the terms and conditions of the Creative Commons Attribution (CC BY) license (http://creativecommons.org/licenses/by/4.0/). 